\title{
A Hydrogen Sulfide Sensor Based on a Surface Acoustic Wave Resonator Combined with lonic Liquid
}

\author{
Yoshinobu Murakawa, Motoaki Hara, Hiroyuki Oguchi, Yuichiro Hamate, and Hiroki Kuwano \\ Department of Nanomechanics, Tohoku University, \\ 6-6-01, Aza-aoba, Aramaki, Aoba, Sendai, 980-8579, Japan \\ hara@nanosys.mech.tohoku.ac.jp
}

\begin{abstract}
:
This paper describes a hydrogen sulfide $\left(\mathrm{H}_{2} \mathrm{~S}\right)$ gas sensor using ionic liquid (IL). In this sensor, a reservoir for the IL was integrated above a surface acoustic wave (SAW) resonator. The IL serves as an absorber for $\mathrm{H}_{2} \mathrm{~S}$ gas. Mass change due to this absorption is detected as a frequency-shift of the resonance. In this study, we fabricated and demonstrated the sensor using the $\mathrm{LiNbO}_{3} \mathrm{SAW}_{\text {resonator }}$ with the resonant frequency of $38 \mathrm{MHz}$. The integrated reservoir was filled by the IL 1-butyl-3methlimidazlium tetrafluoroborate ([BMIM]-[BF $\left.\left.{ }_{4}\right]\right)$. As experimental results, we could observe the linear correlation between the amount of the frequency-shift and the exposure time of the sensor to the $\mathrm{H}_{2} \mathrm{~S}$ gas.
\end{abstract}

Key words: $\mathrm{H}_{2} \mathrm{~S}$, SAW, ionic liquid, gas sensor

\section{Introduction}

Hydrogen sulfide $\left(\mathrm{H}_{2} \mathrm{~S}\right)$ gas is one of the common toxic gases in our life today. Since 2008 , there has been a burgeoning of suicide attempts using the $\mathrm{H}_{2} \mathrm{~S}$ gas, and the fad is escalating into a chain reaction in Japan [1]. The $\mathrm{H}_{2} \mathrm{~S}$ gas is made from household chemicals in the bath or toilet, and is synthesized voluminously more than what is required for an individual suicide. So, it is very deleterious not only for the suicide but also for his family, neighbors, and rescuers. Recently, high sensitive detection of the $\mathrm{H}_{2} \mathrm{~S}$ gas becomes important to make our society safe and comfortable.

In this study, we developed a new type $\mathrm{H}_{2} \mathrm{~S}$ gas sensor based on the surface acoustic wave (SAW) resonator. The SAW technology is mature to detect the mass change and widely accepted as a high sensitive sensor [2-8]. In addition, the SAW resonator is suitable for size shrinkage, suppression of power consumption and integration with RF systems. These advantages are attractive to construct the wireless sensor network to monitor the generation of the $\mathrm{H}_{2} \mathrm{~S}$ gas as a distribution.

To develop the $\mathrm{H}_{2} \mathrm{~S}$ gas sensor, the material to trap the $\mathrm{H}_{2} \mathrm{~S}$ gas and give the mass change to the SAW resonance is a key. The ionic liquid (IL) was spotlighted for such absorber in this study. The IL is molten salts that are liquid over

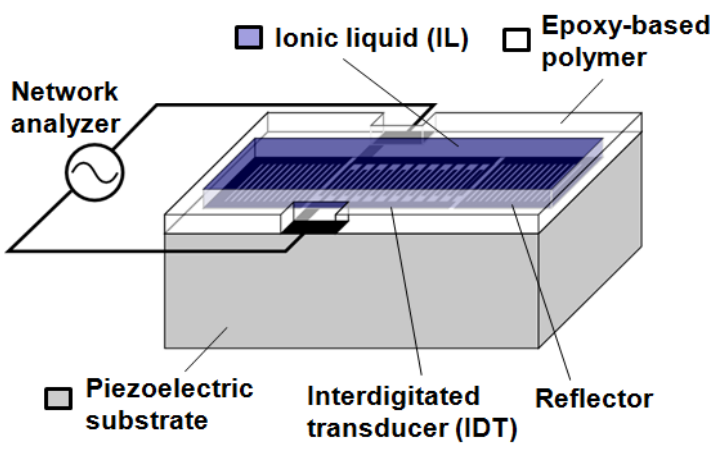

Fig. 1. Schematic illustration of the SAW based $\mathrm{H}_{2} \mathrm{~S}$ gas sensor combined with ionic liquid.

a wide temperature range including ambient temperatures. It has high thermal and electrochemical stability since a vapor pressure of the IL is negligibly small. One of the active research areas of the IL is an application to trap and remove the acid gas $\left(\mathrm{CO}_{2}\right.$ or $\left.\mathrm{H}_{2} \mathrm{~S}\right)$ from sour natural gas [9]. Especially, 1-butyl-3methlimidazlium tetrafluoroborate ([BMIM]$\left[\mathrm{BF}_{4}\right]$ ) has been reported as a useful $\mathrm{H}_{2} \mathrm{~S}$ absorber [10].

Using this IL [BMIM]-[BF $\left.{ }_{4}\right]$ for the absorber on the SAW resonator, the sensor can obtain the high selectivity for the $\mathrm{H}_{2} \mathrm{~S}$ gas, and high stability against a temperature and a pressure in operating environment. 
Piezoelectric substrate

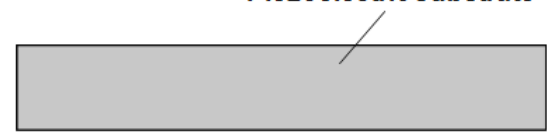

(i) Cleaning with organic solvent

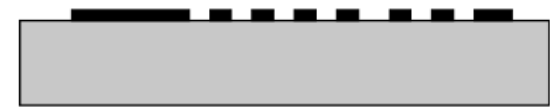

(ii) Evaporating and patterning of $\mathrm{Al}$

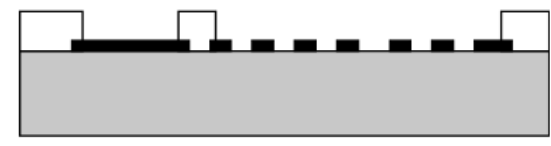

(iii) Patterning and cure

of the epoxy-based photoresist

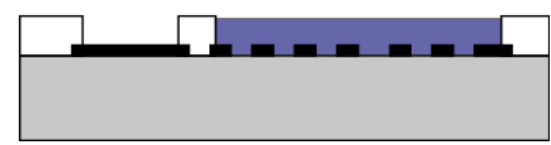

(iV) Pouring the IL into the reservoir

Fig. 2. Fabrication flow of the $\mathrm{H}_{2} \mathrm{~S}$ gas sensor.

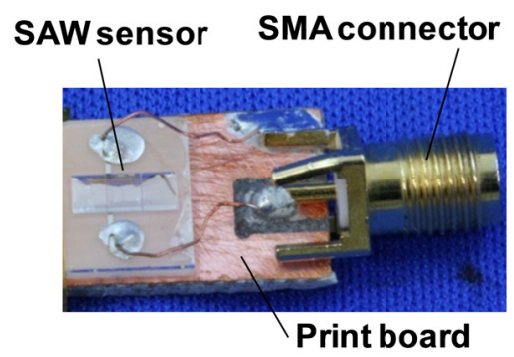

(a)

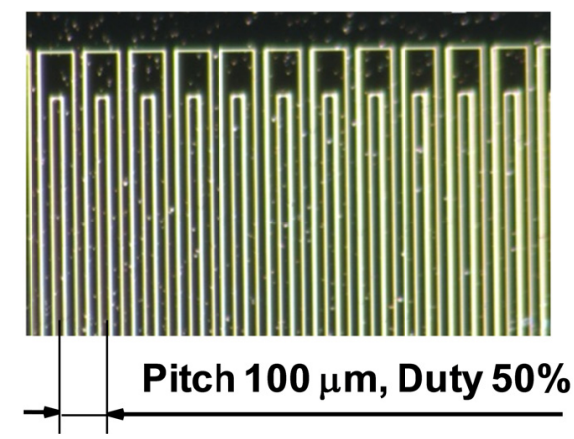

(b)

Fig. 3. Optical micrographs of the $\mathrm{H}_{2} \mathrm{~S}$ gas sensor.

\section{Fabrication}

Figure 1 shows a schematic illustration of the $\mathrm{H}_{2} \mathrm{~S}$ gas sensor we propose. In this sensor, a reservoir for the IL was integrated above a SAW resonator using micro electromechanical systems (MEMS) based technologies. In the SAW resonator, resonant frequency was designed at $40 \mathrm{MHz}$, and the pitch, duty, pair number of the interdigital transducer (IDT), and number of the reflector were set to $100 \mu \mathrm{m}$, $50 \%, 20$ and 40, respectively.

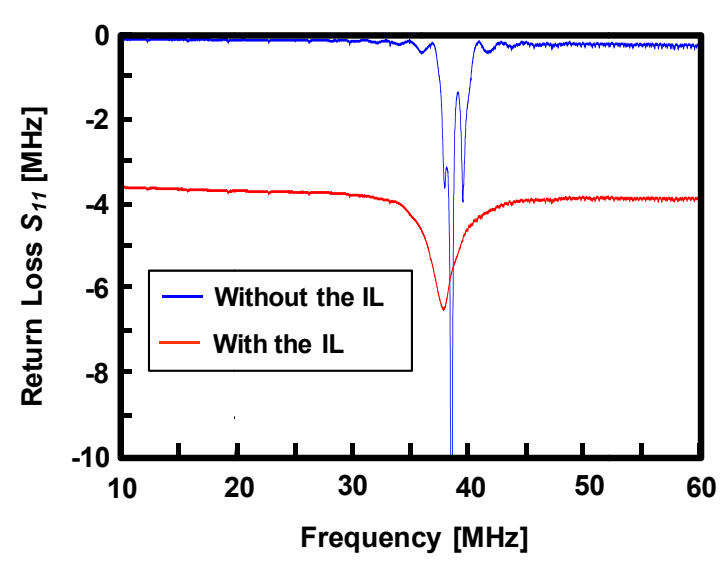

Fig. 4. Resonant characteristics of the $\mathrm{H}_{2} \mathrm{~S}$ gas sensors.

Figure 2 shows a fabrication flow of the $\mathrm{H}_{2} \mathrm{~S}$ gas sensor. At first, $128^{\circ} \mathrm{Y}-\mathrm{X}$ cut $\mathrm{LiNbO}_{3}$ substrate was cleaned by organic solvent in the ultrasonic

bath. And then, aluminum (Al) was sputtered on the substrate to the thickness of $200 \mathrm{~nm}$, and patterned using the etchant, which is a diluted compound liquid of $\mathrm{H}_{3} \mathrm{PO}_{4}, \mathrm{HNO}_{3}$ and $\mathrm{CH}_{3} \mathrm{COOH}$. Using the epoxy-based photoresist (MICRO CHEM: SU-8 3050), the reservoir was fabricated on the resonator. The depth of the reservoir was about $170 \mu \mathrm{m}$. Finally, the IL [BMIM]-[BF $\left.{ }_{4}\right]$ was delivered by drops into the reservoir.

Figure 3 shows optical micrographs of the sensor. The sensor was mounted on the print board and was wired from the pads on the sensor to a RF connector with $\mathrm{Cu}$ wires. Figure 3(b) shows an enlargement of the IDT. It was confirmed that the IDT pattern was fabricated successfully.

\section{Experimental results}

Figure 4 shows resonant characteristics measured from the sensor with and without the [BMIM]- $\left[\mathrm{BF}_{4}\right]$ using the network analyzer (Rohde \& Schwarz: ZVB8). The resonant frequency was decreased from $38.6 \mathrm{MHz}$ to $37.9 \mathrm{MHz}$ by coating the $[\mathrm{BMIM}]-\left[\mathrm{BF}_{4}\right]$. It was also confirmed from Fig. 4 that spurious responses were suppressed though the $Q$ factor was dissipated by the coating.

Figure 5 shows a block diagram of an experimental setup to evaluate the $\mathrm{H}_{2} \mathrm{~S}$ gas detection. The following steps were executed for the evaluation: 1) Evacuating the chamber to the pressure of $1.0 \mathrm{~Pa}: 2$ ) Stopping the evacuation and introducing nitrogen $\left(\mathrm{N}_{2}\right)$ gas to the pressure of $1.2 \times 10^{4} \mathrm{~Pa}: 3$ ) Introducing the $\mathrm{H}_{2} \mathrm{~S}$ gas, and adjusting the pressure to the $4.1 \times 10^{4} \mathrm{~Pa}$ (partial pressure of $\mathrm{H}_{2} \mathrm{~S}$ and $\mathrm{N}_{2}$ were $0.028 \times 10^{4} \mathrm{~Pa}$ and $4.07 \times 10^{4} \mathrm{~Pa}$, 


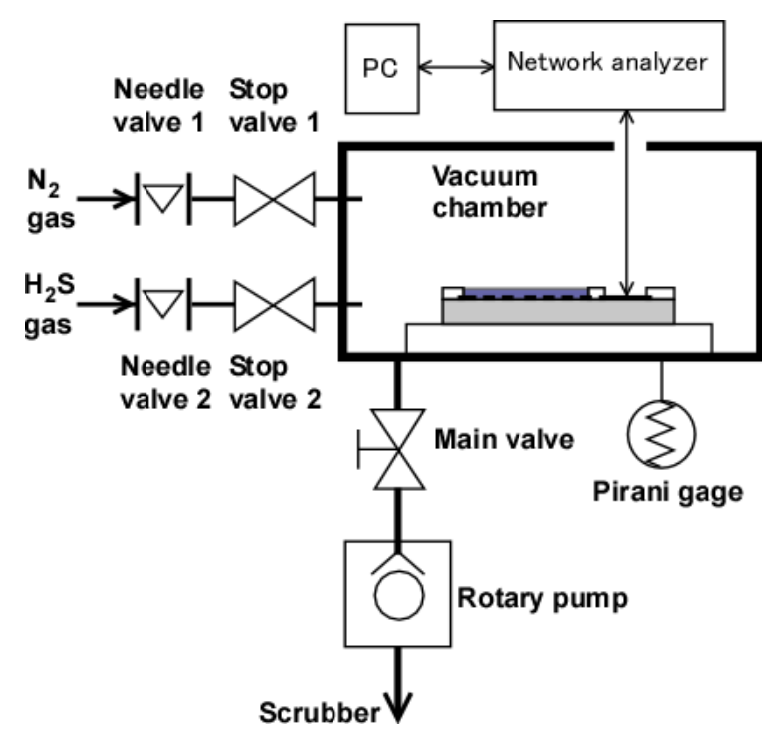

Fig. 5 Experimental setup for evaluation of the $\mathrm{H}_{2} \mathrm{~S}$ gas sensor.

respectively).

Figure 6 shows a variation of the resonant frequency by exposing the sensor to the gasses. When the $\mathrm{N}_{2}$ gas was introduced to the chamber, essential change of the resonant frequency could not be observed. However, it could be observed after the introduction of the $\mathrm{H}_{2} \mathrm{~S}$ gas that the resonant frequency of the sensor was downshifted for the exposure time.

After the above experiments, the resonant frequency could be recovered to the initial frequency by baking in vacuum (degassing). Thus, the sensor can be used repeatedly.

Fourier transform infrared (FT-IR) spectra for the $[\mathrm{BMIM}]-\left[\mathrm{BF}_{4}\right]$ were shown in Fig. 7. Two strong peaks were observed, which were named to $A$ and $B$ in Fig. 7. The peaks indicate a bonding between the cation $[\mathrm{BMIM}]^{+}$and the anion $\left[\mathrm{BF}_{4}\right]^{-}$[11]. These were increased by degassing in vacuum and were decreased by exposing to the $\mathrm{H}_{2} \mathrm{~S}$ gas. From this result, it was grasped that the $[\mathrm{BMIM}]-\left[\mathrm{BF}_{4}\right]$ could trap the $\mathrm{H}_{2} \mathrm{~S}$ gas, and the bonding of ions in the [BMIM][BF $\mathrm{BF}_{4}$ was disturbed due to the $\mathrm{H}_{2} \mathrm{~S}$ absorption.

\section{Conclusion}

Hydrogen sulfide $\left(\mathrm{H}_{2} \mathrm{~S}\right)$ gas is one of the common toxic gases in our life today. To construct the safety and comfortable society, we developed a new type $\mathrm{H}_{2} \mathrm{~S}$ gas sensor based on a surface acoustic wave (SAW) resonator.

In this sensor, a reservoir for the IL was integrated above a surface acoustic wave

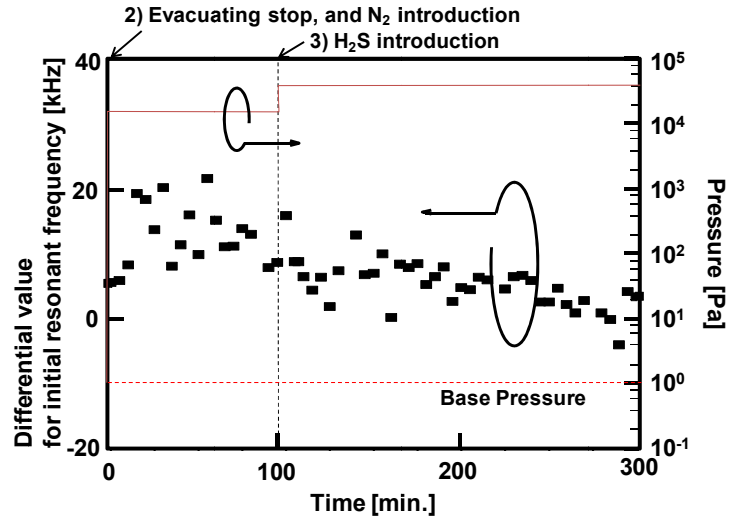

Fig. 6. Variation of the resonant frequency due to the exposing the sensor into the $\mathrm{H}_{2} \mathrm{~S}$ gas.

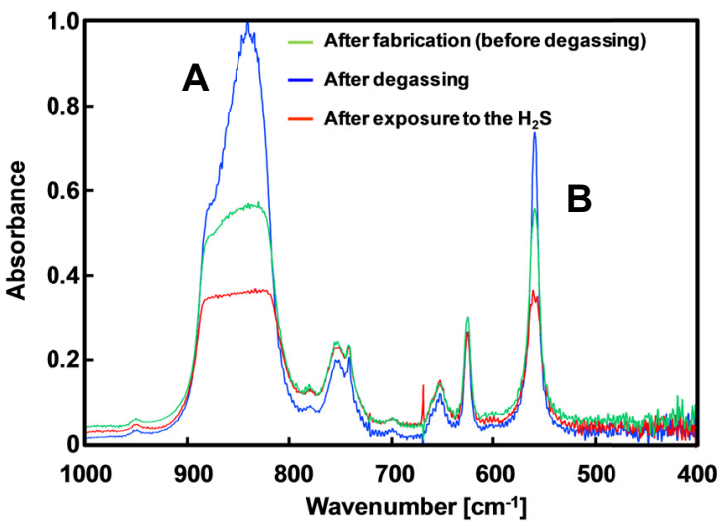

Fig. 7. FT-IR spectra for the $[B M I M]-\left[B F_{4}\right]$.

(SAW) resonator. The IL serves as an absorber for $\mathrm{H}_{2} \mathrm{~S}$ gas. Mass change due to this absorption is detected as a frequency-shift of the resonance. In this study, we fabricated and demonstrated the sensor using the $\mathrm{LiNbO}_{3}$ based SAW resonator with the resonant frequency of $38 \mathrm{MHz}$. The integrated reservoir was filled by the IL 1-butyl-3-methlimidazlium tetrafluoroborate ([BMIM]- [BF4]).

Exposing the fabricated sensor into the $\mathrm{H}_{2} \mathrm{~S}$ gas, we could observe experimentally the linear correlation between the amount of the frequency-shift and the exposure time. From the FT-IR spectra of the $[\mathrm{BMIM}]-\left[\mathrm{BF}_{4}\right]$, it was confirmed that the frequency-shift was induced by trapping the $\mathrm{H}_{2} \mathrm{~S}$ gas to the [BMIM]- $\left[\mathrm{BF}_{4}\right]$.

\section{Acknowledgements}

This study was partly performed in R\&D Center of Excellence for Integrated Microsystems, Tohoku University under the program "Formation of Innovation Center for Fusion of Advanced Technologies" supported by Special Coordination Funds for Promoting Science and Technology. 


\section{References}

[1] D. Morii, Y. Miyagatani, N. Nakamae, M. Murao, and K. Taniyama, "Japanese experience of hydrogen sulfide: the suicide craze in 2008", Journal of Occupational Medicine and Toxicology 5 (28), (2010); doi: 10.1186/1745-6673-5-28

[2] M. Kadota, S. Ito, Y. Ito, T. Hada, and K. Okaguchi, "Magnetic sensor based on surface acoustic wave resonators", Japanese Journal of Applied Physics 50, 1-3 (2011); doi: 10.1143/JJAP.50.07HD07

[3] J. Kondoh, "Liquid-Phase Sensor Using Shear Horizontal Surface Acoustic Wave Devices", IEEJ C Transactions on Electronics, Information and Systems 131, 1094-1100 (2011); doi: 10.1541/ieejeiss.131.1094 [In Japanese]

[4] T. Nomura, T. Kosaka, A. Saitoh, "Passive SAW sensor and its application on strain sensing", IEICE Tech. Rep. ED2004-6, SDM2004-6, 31-36 (2004) [in Japanese].

[5] M. Jubgworth, H. Scherr, R. Weigel, "Micromechanical precision pressure sensor incorporating SAW delay lines", Acta Mechanica, 158, 227-252 (2002); doi: 10.1007/BF01176911

[6] V. Kalinin, "Passive wireless strain and temperature sensors based on SAW devices",
Proc. IEEE Int. Radio. And Wireless Conf., 2004, p.187-190;

doi: 10.1109/RAWCON.2004.1389104

[7] J. Beckley, V. Kalinin, "Non-contact torque sensors based on saw resonators", Proc. Annu. IEEE Int. Freq. Cont. Symp, 2002, p.202-213; doi: 10.1109/FREQ.2002.1075878

[8] B. Donohoe, D. Geraghty, G. O'Donnell, "Wireless calibration of a surface acoustic wave resonator as a strain sensor" IEEE Sensors Journal, 11, 1026-1032 (2011); doi: 10.1109/JSEN.2010.2070492

[9] E. Bates, R. Mayton, I. Ntai, and H. Davis. Jr, " $\mathrm{CO}_{2}$ capture by a task-specific ionic liquid", Journal of American Chemical Society 55, 926927 (2002); doi: 10.1021/ja017593d

[10] A. Jalili, M. Rohmati-Rostami, C. Ghotabi, M. Hosseini-Janab, and A. Armadi, "Solubility of $\mathrm{H}_{2} \mathrm{~S}$ in ionic liquids $[\mathrm{bmim}]\left[\mathrm{PF}_{6}\right],[\mathrm{bmim}]\left[\mathrm{BF}_{4}\right]$, and [bmim] $\left[\mathrm{Tf}_{2} \mathrm{~N}\right]$ ", Journal of Chemical and Engineering Data 54, 1844-1849 (2009); doi: 10.1021/je8009495

[11] J. Andanson, F. Jutz, and A. Baiker, "Supercritical $\mathrm{CO}_{2}$ /ionic liquid systems: what can we extract from infrared and Raman spectra", Journal of Physical Chemistry B 113, 1024910254 (2009); doi: 10.1021/jp90444 